\title{
Multimodal Metaphor in Ten Dutch TV Commercials ${ }^{1}$
}

\author{
Charles Forceville \\ Dept. of Media Studies, University of Amsterdam \\ Turfdraagsterpad 9 \\ 1012 XT Amsterdam, The Netherlands \\ c.j.forceville@uva.nl
}

\begin{abstract}
Since the publication of Lakoff and Johnson's Metaphors We Live By (1980), conceptual metaphor theory (CMT) has dominated metaphor studies. While one of the central tenets of that monograph is that metaphors are primarily a phenomenon of thought, not of language, conceptual metaphors have until recently been studied almost exclusively via verbal expressions. Another limitation of the CMT paradigm is that it has tended to focus on deeply embedded metaphors rather than on creative metaphors of the kind that Black (1979) discusses. One result of this focus is that relatively little attention is paid in CMT to the form and appearance a metaphor can assume (cf. Lakoff and Turner 1989). Clearly, which channel(s) of information (language, visuals, sound, gestures, among others) are chosen to convey a metaphor is a central factor in how a metaphor is construed and interpreted. A healthy theory of metaphor as a structuring element of thought therefore requires systematic examination of both its multimodal and its creative manifestations. Conversely, research into non-verbal and multimodal metaphor can help the theorization of multimodality.

In this paper it is shown that creative metaphors occurring in commercials usually draw on a combination of language, pictures, and non-verbal sound. After an inventory of parameters involved in the analysis of multimodal metaphors, ten cases are discussed, with specific attention to the role of the various modes in the metaphors' construal and interpretation. On the basis of the case studies, the last sections of the paper discuss three issues that are crucial for further study: (1) the ways in which similarity is cued in multimodal, as opposed to verbal, metaphors; (2) the problems adhering to the verbalization of multimodal metaphors; (3) the influence of textual genre on the interpretation of multimodal metaphors.
\end{abstract}

\section{Introduction}

Lakoff and Johnson, the fathers of conceptual metaphor theory (CMT) usefully describe the essence of metaphor as "understanding and experiencing one kind of thing in terms of another" (1980: 5). CMT is committed to the view that human cognition is organized, in skeletal form, in conceptual schemas. Conceptual schemas "constitute cognitive models of some aspect of the world, models that we use in comprehending our experience and in reasoning about it. Cognitive models are not conscious models; they are unconscious and used automatically and effortlessly" (Lakoff and Turner 1989: 65-66). Such schemas are constantly enriched and, if necessary, modified by people's interactions with the world. Language draws on these cognitive models, but is not identical with them. Consequently, verbal metaphors are no more and no less than surface manifestations of metaphorical thinking, so that metaphor is " fundamentally conceptual, not linguistic, in nature" (Lakoff 1993: 244). Cognitivist metaphor scholars, many of them trained as linguists or literary theorists, have widely explored this issue (e.g., Lakoff and John-

\footnotetext{
${ }^{1}$ The videos can be viewed on the Flash version of this article: http://www.semiotics.ca/issues/pjos-1-1.swf
} 
son 1980, 1999, 2003; Lakoff 1987; Johnson 1987, 1993; Lakoff and Turner 1989, Kövecses 1986, 2000, 2002, 2005; Sweetser 1990; Turner 1991, 1996; Gibbs 1994, Gibbs and Steen 1999, Charteris-Black 2004).

A limitation of the work by CMT researchers is that they have almost exclusively restricted their investigations to language and paid little attention to non-verbal manifestations of conceptual metaphor. This neglect is unfortunate for at least two reasons. First, there is the risk that by exclusively focusing on verbal manifestations of metaphor, the modelling of the cognition level becomes a mere mirror of that of the verbal level, and will fail to reflect any characteristics that are found in non-verbal and multimodal metaphors but not in verbal ones. Clearly, only part of the knowledge that feeds into conceptual schemas is verbal in nature, or can easily be formulated in verbal terms. Conversely, CMT's potential as instrument in the analysis and theorization of multimodal representations, ranging from advertisements and feature films to instruction manuals and internet sites, currently remains underused.

This situation is slowly beginning to change. Research on pictorial metaphor has over the past 25 years yielded a fair number of theoretical studies (Kennedy 1982, forthcoming; Forceville 1988, 1994, 1996, 1999a, 2000, 2002a, 2002b; Whittock 1990; Kaplan 1990, 1992; Danto 1993; Carroll 1994, 1996; Rozik 1994, 1998; Maalej 2001, Rohdin 2003, Cupchik 2003; El Refaie 2003; Kennedy 1993 is exceptional in being informed by experimental findings). But purely pictorial metaphors - metaphors in which the signalling of the two terms of a metaphor, target (tenor, topic) and source (vehicle, base) is achieved by visual means only - are relatively rare. Once we leave the realm of the verbal, usually either or both of the terms are cued in more than one channel simultaneously. Indeed, one of the four types of pictorial metaphor distinguished in Forceville (1996, 2000), the "verbo-pictorial metaphor," in fact straddles two modes and is, in retrospect, better labelled a subtype of multimodal than of pictorial metaphor. Many, probably most, non-verbal metaphors are thus multimodal metaphors. A multimodal metaphor is here defined as a metaphor whose target and source are not, or not exclusively, rendered in the same mode. The five modes taken into consideration in this paper are (i) written language; (ii) spoken language; (iii) visuals; (iv) music; (v) sound. This list is not exhaustive or definitive: on the one hand these modes could be further subdivided (visuals comprise aspects of mise-en-scene, montage, as well as framing angles, and these arguably deserve the status of a separate "mode"); on the other hand certain sources of perceptual information, such as gestures, are not discussed here, while these may also lay claim to the label of constituting a "mode" (see McNeill 1992, Cienki 1998, Müller 2004). But the possibility of refining and extending the list of possible modes involved in multimodal metaphor does not affect the basic principles adhered to in this paper.

Makers' intentions are an important factor in discussions about metaphor. I subscribe to Gibbs' (1999) views on the centrality of intention in the interpretation of human artefacts in general. Such views are commensurate with Sperber and Wilson's Relevance Theory (Sperber and Wilson 1995; Wilson and Sperber 2004; see Forceville 1996, Chapter 5; 2005a for applications in the realm of pictorial and multimodal representations). Within the context of studies of non-verbal metaphor, both Kennedy (1982) and Whittock (1990) stress that the construal of metaphors typically presupposes some authorial intention: the author usually wants a certain combination of perceptual elements to be understood as a metaphor (rather than, 
say, as nonsense, or as merely aesthetically pleasing). Imagine a cinematic shot of a giraffe, saliently accompanied by the trumpeting sound of an elephant in such a way that the trumpeting appears to emanate from the giraffe. Let us assume that the viewer-cum-listener believes that the filmmaker did not erroneously or whimsically give this impression, and that there is no good non-causal relation between the giraffe and the trumpeting sound (as would be the case, for instance, when the viewer understands the sound as being produced by an off-screen elephant that happens to trumpet at the same moment the camera shows the giraffe, for instance in a zoo). In such a case she would probably interpret the co-occurrence as intentional, and construe the multimodal metaphor GIRAFFE IS ELEPHANT - or perhaps ELEPHANT IS GIRAFFE - and search for a pertinent meaning. Since one of the terms is represented visually and the other sonically, the metaphor would be a multimodal one.

In this paper I will investigate multimodal metaphors in ten Dutch commercials, with the following aims: (1) to chart the minimal parameters governing multimodal metaphor; (2) to demonstrate that metaphors occurring in moving images usually draw on more than one channel of information; (3) to signal several issues pertaining to multimodal metaphor that require further consideration. The investigated representations will here, as in Forceville (1996), belong to the genre of advertising, because unlike for instance artistic representations, advertising has straightforward purposes: the bottom line is that it makes positive claims about a product or service (Forceville 1996: 104), however unglamorous or self-mocking it may be. This fact unequivocally steers and constrains the construal and interpretation of any meaningful element a commercial might contain, thus making commercials an exemplary genre for the development of a model of multimodal metaphor.

\section{Multimodal versus pictorial metaphor}

In Forceville (1996: 108) I argue that a phenomenon deserving the label "metaphor" needs to have at least the following characteristics: It has two terms that, in the given context, belong to different categories; one of these terms can be construed as the "literal" target, and the other as the "figurative" source; and one or more features of the source must be mappable on the target, which by this mapping is (temporarily) transformed. Adaptation of the categories and terminology in Forceville (2002) leads to the following types of pictorial metaphor, including one which was not yet distinguished in my earlier work (the old names are given in brackets):

(1) Contextual metaphor (MP1). One term is depicted; the other is not depicted but unambiguously suggested by the pictorial context. Removal of the pictorial context results in the disappearance of the second term, and hence in non-metaphor. In most cases the pictorially present term is, or refers metonymically to, the product advertised. While (mentally) removing the verbal context does not usually affect the identification of the two terms, such removal may render difficult or impossible their characterization as target and source - and hence make the interpretation of the metaphor as a whole problematic.

(2) Hybrid metaphor (MP2).Parts of both terms are pictorially represented, resulting in a hybrid phenomenon perceived as a single gestalt. Removal of the pictorial context - if present in the first place - still allows for identification of both terms. Removal of the verbal context does not affect the identification of the two terms, although it may render difficult or impossible their characterization as target and source respectively, and hence the interpretation of the metaphor as a whole. 
(3) Pictorial simile (Pictorial simile). Both terms are pictorially represented in their entirety. Removal of the pictorial context - if present in the first place - still allows for identification of both terms. Removal of the verbal context again does not affect the identification of the two terms, although it may render difficult or impossible their characterization as target and source respectively, and hence the interpretation of the metaphor as a whole.

(4) Integrated metaphor. A phenomenon that is experienced as a unified object or gestalt is represented in its entirety in such a manner that it resembles another object or gestalt even without contextual cues. This type is identified by Van Rompay (2005) and Van Rompay et al (2005), in turn drawing on Lakoff and Johnson's work ("embodied metaphor" would be an appropriate name for this type, but given the strong and partly different connotations "embodiment" has in the Lakoffian tradition I prefer to avoid it here). An example is a Philips Senseo coffee machine, which is stylized in such a way as to represent a servant or butler. (I owe the example to Paul Hekkert. For more discussion, see Forceville et al., forthcoming; for examples and discussion of the other types see Forceville 1996: Chapter 6 and Forceville 2005b).

When contrasted to pictorial metaphors in printed ads and billboards, metaphors in television commercials (a commercial is here defined as "advertisement, announcement, spot or message aired on television, radio or cable which is paid for by an advertiser"2 differ potentially in the following dimensions:

1. Since commercials unfold in time, target and source need not be represented (or unequivocally suggested) at the same moment; that is, they can be presented sequentially.

2. A metaphorical term (target or source) can be presented not only visually or verbally, but also sonically, by means of a musical theme or a non-verbal sound.

3. Framing and camera movements provide formal means to (help) establish metaphoric similarity not available to singular static images (although they are available to, for instance, multi-panel cartoons or series of pictures in comics).

Before turning to an examination of multimodal metaphors in commercials, a matter of terminology needs to be clarified. Just as verbal metaphors, pictorial metaphors are monomodal metaphors. Monomodal metaphors will here be defined as metaphors whose two terms are predominantly or exclusively rendered in the same mode. Hitherto mainly monomodal metaphors of the verbal and pictorial variety have been described and analysed, but there is no reason to rule out the possibility of monomodal metaphors of a sonic, musical, gestural, olfactory, or tactile nature. I will not go into detail, but here are some examples of what I have in mind. Imagine a mime artist on some touristy square briefly following passers-by and imitating their gait (as, for instance, in the opening sequence of Francis Ford Coppola's The Conversation, USA 1974). The mime could exaggerate people's step in such a way that the metaphor PASSER-BY IS A DANCER is cued, or PASSER-BY IS A DRUNK. Monomodal metaphor of a musical variety appears possible as well (see Johnson \& Larson 2003 for references; see also Cook 1998). Thorau (2003) proposes that the relation between a musical theme and its variation

${ }^{2}$ http://www.nielsenmedia.com/glossary/terms/C/ 
can be metaphorical: The theme functions as target and its variation as the source. He gives the example of Ludwig van Beethoven's Six Variations op. 34 (1802), focusing on variation $\mathrm{V}$, arguing that the Adagio theme (the "target") transforms into a "march" (the source). For the trained listener, thanks to the metaphorical coupling with the march variation, certain latent aspects of the theme have been made salient that had not been noticeable without it. For what we could consider a tactile metaphor, picture the following scene. An old, blind woman has developed excessive hair-growth on her arms. Her daughter wants her little son to stroke his grandmother, because the grandmother likes such physical intimacy with her grandchild. The boy, however, finds the hairy grandmother repellent. To help her son overcome his repugnance, the mother lets him first stroke his favourite fluffy pet bear, to feel its softness, and then encourages him to stroke his grandmother. I submit that this example would qualify as a tactile metaphor of the monomodal variety, to be verbalized as something like GRANDMOTHER'S HAIRINESS IS PET BEAR'S FLUFFINESS, with the pleasant, positive connotations of the source being mapped onto the target. A monomodal metaphor of the olfactory variety could be this: Two researchers in the lab of a perfume factory have been ordered to develop a new perfume, preferably one that will prove as commercially successful as Chanel 5. One of them thinks she has created an excellent essence. She first lets her colleague smell Chanel 5, and then the experimental essence. Let us assume that the latter has, as one of its olfactory layers, something that is strongly reminiscent of Chanel 5, but is nonetheless sufficiently different not to be disqualified as a copy. We could then say that the first researcher offers her colleague an olfactory metaphor, NEW PERFUME IS (LIKE) CHANEL 5, with "marketability" as the primary mappable feature. I will not pursue this line of speculation. What matters for present purposes is that monomodal metaphors contrast with multimodal metaphors, metaphors whose target and source are cued in two or more different modes. As the unusualness of the examples given above already suggest, outside of the realm of written verbal specimens most metaphors are presumably of the multimodal rather than of the monomodal variety.

As holds for any type of metaphor, the understanding of a multimodal metaphor begins with the awareness that two phenomena can or must be understood as being in an identity-relation. There must be a reason not simply to spot two different phenomena A and B as both "present" in a representation, but to process A as $\mathrm{B}$, in one or more respects (Freriks 2004). As indicated above, an intention to produce a metaphor usually results in the provision of salient cues to that effect by the metaphor's producer. In the first place, some sort of similarity between A and B must be signalled. In the type of ad hoc metaphors that surface in advertising, this similarity is often not pre-existent, but created (Black 1979). The similarity may be of many different kinds: A and B may look similar, sound similar, occur in a similar space or, as in the giraffe-elephant case, be simultaneously signalled (see Forceville 2004, Bensdorp and Vergeer 2004, Victor 2004). A second type of cue that an A-as-B interpretation may be called for is that there is something odd or anomalous in the identification of $\mathrm{A}$ and $\mathrm{B}$, because in the given situation $\mathrm{A}$ and $B$ are experienced as entities belonging to different categories and do not normally constitute a single entity. The qualification "in the given situation" is necessary, for categorization is a goal-driven activity, and two entities that in one situation belong in the same category will in another situation be considered to be in different categories. Whether and, if so, how a metaphor is to be construed is to a considerable 
extent governed by expectations pertaining to genre. A crucial genre convention in advertising is that a positive claim is made for a product or brand. Viewers of a commercial will thus routinely assume (a) that they will be able to identify a product or brand; and (b) that every meaningful element in a commercial that is not the product itself somehow helps facilitate the creation of a positive brand image. These assumptions combined will strongly steer viewers' interpretations.

\section{Ten multimodal metaphors: descriptions}

In this section, ten Dutch commercials, broadcast on Dutch television channels in 2004 are analysed that, I claim, all contain a multimodal metaphor. A link to an online version is provided when the commercial is discussed; and any translations into English are mine. The purpose of these analyses is to demonstrate, via real-life examples, what forms multimodal metaphors can assume. Each analysis begins with a description, and is followed by a consideration of the various modes involved in the cueing of the metaphor.

The recognition of a metaphor crucially requires the identification of a target and a source. For both target and source holds that it must be recognizable in one or more of the following ways:

1. It is visually represented, counting as such if it is either itself depicted, or one or more elements metonymically related to it are depicted.

2. It is sonically represented, counting as such if a non-musical, non-verbal sound unambiguously associated with it is used to cue its identification.

3. It is musically represented, counting as such if a musical theme unambiguously associated with it is used to cue its identification.

4. It is represented in spoken words, counting as such if an on-screen character or a voice-over identifies it, or if one or more elements metonymically related to it are voiced.

5. It is represented in written words, counting as such if it, or one or more elements metonymically related to it, appears in written form onscreen ("supers").

A caveat pertains to the cultural context in which the metaphors originate. Certain connotations of the source domains appeal only to a Western, European, Dutch, or even Dutch-subgroup community - or may simply be idiosyncratically perceived ones, bearing out Sperber and Wilson's important insight that relevance is always relevance to an individual (Sperber and Wilson 1995: 142). Since this holds for all representations, this is not considered a problem; indeed, it will alert readers/viewers to how representations can be (mis)interpreted by certain groups or individuals in manners unforeseen or unintended by their producers.

Example 1. Gazelle bicycles. The Dutch dressage champion Anky van Grunsven (gold medal winner both at the Olympic games in Sydney 2000 and Athens 2004), dressed in her black coat, white breeches and top hat, tells us: "If you go for gold, you have to be seated well in the saddle. ${ }^{3}$... And I should know, shouldn't I?" The image track shows us cross-cuts from Anky sitting on a school horse, and Anky riding a Gazelle bicycle - an old and very familiar brand of bicycles in The Netherlands. She praises the beauty and excellent seating comfort ("zithouding")

\footnotetext{
${ }^{3}$ There is a pun here on the Dutch expression "vast in het zadel zitten," meaning something like "being well-equipped for whatever it is one intends to do."
} 
of the bike and ends with "op zo'n raspaardje zit je dus altijd goed." This literally translates as "you are always well-seated on such a thoroughbred," but the word "raspaardje" ("thoroughbred") in Dutch has acquired the generic meaning of something or somebody with exceptional qualities, while the expression "je zit altijd goed (met)" means "you can't go wrong (with)." "Sorry Bonfire," she apologizes to the horse many viewers know is her championship-winning favourite who, at that time, has retired. The last shot before the pay-off features a gazelle (the animal), instead of a horse, in the stables, humorously suggesting Van Grunsven has now done with horses, and opts for gazelles instead. The metaphor promoted here is GAZELLE BIKE IS THOROUGHBRED. The features that can be mapped from Van Grunsven's horse to the bicycle comprise the alleged "seating comfort" and its physical beauty. More importantly, the relation of Van Grunsven and her prizewinning horse can be projected onto (future) Gazelle-owners and their Gazelles. This potentially bestows connotations such as glamour, prize-winning, fame etc. on the bike and its prospective user.

The metaphorical similarity is created first and foremost by the visual juxtaposition of the officially-dressed Anky on her horse and the officially-dressed Anky on a Gazelle bike, and partly by expressions like "being well in the saddle" and "thoroughbred." The fact that the brand name of the bicycle is the name of an animal further reinforces the similarity with Anky's horses. Although some clicking is audible when Van Grunsven adjusts the bicycle's saddle, this is insufficient in itself to suggest the identity of the object producing this sound - the Gazelle bicycle, or even "bicycles" generically - and hence the target cannot be considered to be cued sonically. The source "horse," by contrast, is recognizable thanks to the clip-clopping of its hooves and its snorting. Since Van Grunsven explicitly mentions the brand name Gazelle in her voice-over text, the target is represented in spoken form as well. The source domain is present in spoken form in expressions like "being in the saddle" (which of course also cues the target) and "raspaardje" ("thoroughbred"). The music, a quiet tune apparently produced by an electric guitar, does not cue either target or source. One other element helps cue the source domain, and that is Van Grunsven's voice, since it is well-known and uniquely connotes her. Hence, even apart from what Van Grunsven says, to a wide audience her voice alone evokes the domain of horse-dressage. Though in practice inseparable from the words she utters, Van Grunsven's voice thus can be said to constitute a sonic evocation of the source domain, just as the horse's hooves and whinnying do.

Example 2. Dove body lotion. In a fast montage of close ups we see white thread winding itself on a wooden spindle After a few seconds a female voice-over comments, "Silk reflects each ray of light. Hardly surprising, then, that it is so beautiful on your skin." The next shot shows the "spindle" standing upright, while the silk quickly unwinds to reveal a bottle of Dove Silkening Body Moisturizing, suggesting the metaphor DOVE BODY LOTION IS SILK. Mapped features are silk's potential to reflect light as well as, presumably, its softness. In addition one can be reminded of silk's status as a prestigious and expensive fabric.

The target is rendered both pictorially and verbally, the latter in spoken as well as written form (on the Dove bottle). The source, silk, is presented visually (although the white thread is not identified as "silk" until the voice-over labels it so) and orally: the female voice-over tells us the product contains pure silk, "for a natural glow and a silky-soft skin." The commercial features suave, eerie electronic sound 
(music?) throughout. While it may be understood as enhancing the "softness" of the product, this sound does not seem to belong explicitly to either target or source.

Example 3. Philips Sonicare toothbrushes. The visual track shows a toothbrush slowly emerging vertically from the water. Beeping sounds are audible in the background. The female voice-over talks about the "next generation of electric toothbrushes by Philips, with patented sonic technology ... a totally new brushing experience," and praises its technology, ending with the (originally English) pay-off, which also appears in written supers on the screen, "Stop brushing, start Sonicare." The toothbrush emerging from the water resembles a surfacing submarine, a resemblance reinforced by the similarity between the toothbrush's head and a submarine's periscope: hence the metaphor is TOOTHBRUSH IS SUBMARINE. Mappable features include submarine high-tech, while the notion of the toothbrush's novelty is reinforced by the "surfacing" of the submarine-toothbrush.

A phrase in the upper left hand of the screen specifies the metaphor's target: "Philips, the sonic toothbrush." The verbal track does not, by contrast, mention the word "submarine" or any words specifically associated with its semantic domain either orally or in written form. The "beeping sounds," however, probably help identify the source domain as something "high-tech." The sound track moreover has a choir singing "Aaaahhh," in a manner that in some viewers may evoke generic associations with science fiction scenes in which a good-natured extra-terrestrial creature or spaceship gradually becomes visible. This eerie, "alien" effect is further reinforced by the fact that when the toothbrush appears, the water does not ripple outwards from the toothbrush but, "unnaturally," inwards toward it (the original footage was, no doubt, played in reverse). Inasmuch as the science fiction association does not adhere to "submarines," it is not part of the metaphor, while still contributing to the overall potential meaning of the commercial.

Example 4. Citroen cars. The commercial under consideration is part of a series in which the protagonist is always the same Citroen salesman who, even when offduty, cannot resist sharing his enthusiasm for the brand he sells. In the current version, he opens his front door at home to a man and a woman who ask him whether he has a little time for them. They are pleasantly surprised when he jovially invites them in for coffee. When seated, the man of the couple begins to say, "I would like to tell you something very beautiful about ..." but he is rudely interrupted by the salesman, who begins to rattle off the qualities of the newest Citroen car model, never giving his interlocutor a chance to take the floor again. When the couple beats a hasty retreat the salesman tries to fob a pile of Citroen brochures on them, saying, "if you are going from door to door anyway ..." The implied metaphor here is CITROEN SALESMAN IS EVANGELIST; the mapped feature is, say, the presumed zeal, authenticity, and passion with which evangelists preach their message. Moreover, the evangelists' "beauty" as pertaining to their religious message is humorously transformed (or perhaps one should say: perverted) into the beauty of the car.

Target and source are visually and verbally represented, although the Citroen salesman would probably not be identifiable as such without his spoken text - unless one were to recognize him from earlier commercials in the same series. It is to be noticed that when the couple hasten to leave the unstoppable salesman, it is the latter who puts his (stockinged) foot between the door to prevent it from being slammed - another subtle way of cueing the metaphor's source domain, and a hint 
that he outsmarts the evangelists at their own game. The visiting man's face, his pious voice, and the couple's bland clothes help reinforce the cliché of evangelists.

Example 5. Airwick air freshener. A woman visiting a museum looks up closely into a reflecting modern sculpture as if it were a mirror, and walking backwards accidentally knocks another, glass sculpture from its pedestal, shattering it to pieces. She is horrified, but quickly fetches an aesthetically designed Airwick Crystal'Air holder from her bag, fills it with blue Crystal'Air freshener, and puts it on the pedestal. A female voice-over tells us that "New Crystal' Air Design is full of real perfume that spreads continually, day after day, during six weeks." In the mean time several other visitors have gathered around the "sculpture," commenting, "this work of art smells beautifully!" and "What a delicious smell!" The metaphor AIRFRESHENER IS WORK OF ART allows for the mapping of "aesthetically pleasing" or "high-culture prestige" from the artistic sculpture to the air freshener.

Although the source domain art in the metaphor CRYSTAL'AIR IS A WORK OF ART is reinforced verbally by the comments of a visitor, the visuals have already cued it via the presence of the other sculptures in a typical, white-walled museum room. The sound we hear when the woman puts the Crystal'Air holder on the pedestal is that of a glass object being placed, subtly underlining the similarity with the - aurally cued - shattering of the glass art object. The respectful silence, in combination with the echoes of clicking shoes, further helps identify the source domain, as does the poster "Museum [of] Modern Art" on the wall at the far end.

Example 6. Brand Cuvée beer. A close-up shows a corkscrew that, at the end of a panning shot to the right, turns out to be a corkscrew-cum-bottle-opener. The device is picked up, and we hear a beer bottle being snapped open. A male voice-over comments: "A soft and supple taste. A clear but warm colour. And a fresh, but light, fruity aftertaste. Now try Brand Cuvée as well. One of the three pilseners from the Brand collection." Clearly, the metaphor suggested is BRAND CUVÉE BEER IS QUALITY WINE. Any positive characteristic of, and typical behaviour toward, a quality wine is potentially mapped on the beer: high cultural prestige, something to drink on a romantic evening, a drink to cherish, and something one is willing to pay more for than for your average alcoholic drink - such as ordinary beer. Whether these implied claims are to be taken at face value or as presented with deadpan, tongue-in-cheek humour is up to the viewer.

Most important for the cueing of the source domain WINE is the corkscrew. In addition, Cuvée is familiar to connaisseurs as a phrase used in wine names. Thirdly, the verbal references to the drink's colour and its "fruity aftertaste" typically connote wine-drinking. The allusions are sometimes picked up in a five-second reinforcement, shown a few commercials later, in which the voice over continues, "Order the real Brand glasses now, and you will temporarily receive the "Taste guide' for free. Look on Brand.nl," while we see three types of beer glasses on the left of the screen and a shot of the "Taste guide" on the right. Another commercial in the series deploys the same metaphor: a man descends into what appears to be a wine cellar and carefully takes two bottles from a whole range of horizontally laid out bottles; only when they appear in close up we see they are Brand beer, not wine, bottles.

Example 7. Basics sports shoes. A pair of sports shoes stands on the floor in front of a TV set which, judging from the stadium sounds emanating from it, features a sports programme. Two male voice-overs, seemingly belonging to the shoes, are 
involved in a dialogue. The details of this commercial, which has other variants in the same series, are not relevant here: the point is that the verbal soundtrack personifies the shoes, yielding the metaphor SHOES ARE MEN. This commercial, and others in the same series, was broadcast frequently in the weeks preceding and during the Olympic Games in Athens (2004).

The sports shoes are personified almost entirely through the voice-overs (with the combined aspects of conveying verbal information, i.e., spoken language, and the humanness of the producers of this information, i.e., sound) alone. They do not, for instance, move. We are tricked into believing that it is the shoes that are speaking by a combination of the following considerations: they are filmed continually, often in close-up, and there is no other possible source for the voices; the shoes' position in front of the TV suggests they are watching; during the first part of the commercial, the switch from one voice to the other in the dialogue coincides with a cut, which suggests something akin to shot/reverse-shot editing (Bordwell and Thompson 1997: 288). With the sound switched off, however, probably few viewers would be aware of the shoes' personification.

Example 8. Peugeot car. In a realistic big-cityscape we see, in a quick montage accompanied by a techno tune, the one non-realistic thing: all the cars are brightlycoloured toy cars. They are life-size copies of the type children play with - some plastic, some wooden, some with the passengers painted on the windows, some with a windup key sticking out. Many people look up, astonished, with envy, or admiringly, in the direction of the camera. The reason for this becomes clear once we realize that the camera shots are point-of-view shots taken from a car, namely from the Peugeot 407 that in sharp contrast with all the other cars is a real car. The commercial ends with three shots with the following supers: "The new Peugeot 407"; "At last a car again"; "You feel better in a Peugeot," accompanied by the Peugeot logo. The metaphor can be verbalized as NON-PEUGEOT CAR IS TOY CAR. The mapped feature is the source's artificiality and its status as meant for children.

The toy car domain becomes identifiable quickly, and its oddness in the realistic cityscape is immediately obvious, but it is not until the toy cars are explicitly juxtaposed to the Peugeot (first by a shot of it, and then elaborated on by the line "at last a car again") that we realize we need to construe a metaphor in which the toy cars constitute the source domain. It is to be emphasized that this metaphor does not have the product (Peugeot) as the target of the metaphor, but rather its antonym: the competitors whose products the viewer, according to the advertiser, of course does not want to buy.

Example 9. UWV job support. UWV is an umbrella organisation entrusted with assessing people's right to unemployment benefits as well as the height and duration of the payments, and is responsible for issuing them. In addition the organisation is charged with preventing unemployment and monitoring the reintegration of unemployed and disabled people. The commercial opens with a view of a wharf, where we see a welder at work. When he looks into the camera, a female voice over says "team player" and the word appears on screen simultaneously. In the same manner we see a man tarring a hull ("roll champion"); a man at a lathe ("magician"); and an overseer ("price controller"). In each case there are diegetic sounds pertaining to the target domain (e.g., the tarrer's rolling movements are audible, as is the lathe). The music consists of soft, unobtrusive guitar strumming. Over 
a shot where all four workers together with some other colleagues look into the camera, the voice-over addresses employers thus: "Be careful with your capital. Consult with your employees and your ARBO-agent [a Dutch Occupational Health and Safety institution negotiating conditions under which employees with health problems can get back to work] how you can prevent disability." The last shot shows the UWV logo, the website address and the pay-off "Preventing is saving: prevent disability."

The commercial shows four multimodal metaphors of the verbo-pictorial variety; WELDER IS TEAM PLAYER; HULL-TARRER IS ROLL CHAMPION; LATHE-OPERATOR IS MAGICIAN; OVERSEER IS PRICE CONTROLLER. Arguably, in the fourth case there is not, strictly speaking, an incongruence between two different domains (an overseer can literally be a price controller), but the source domain still makes salient an aspect in the target that is normally is not, and in that sense invites the addressees (here: employers) to consider their employee in a new light. Such an example, incidentally, is a reminder that there may be a continuum between pure metaphors ( $\mathrm{A}$ is $\mathrm{B}$ ), in which two different domains are compared non-literally, and role-attribution (A IN THE CAPACITY OF B) where it is significant that both are covered by the familiar characterization "seeing/understanding A-as-B."

Example 10. Harpic toilet brush. An excited male voice-over, accompanied by an upbeat tune exhorts us, partly using English words and phrases (here indicate by italics): " Get set ready... For the new Harpic Ready Brush. The new weapon in the realm of daily toilet hygiene. Ready, aim, and... brush!" and gives some more details about the product. The visuals show us how the three parts of the blue-andwhite brush and the cartridge with the cleansing liquid assemble themselves. A blond woman is seen cleaning a toilet. The last shot has the super "Also in refill packaging." In the metaphor TOILET BRUSH IS WEAPON, the mappable features of the source domain presumably include a tongue-in-cheek heroism.

While the visuals alone hardly suffice to indicate that the construal of a metaphor is in order, the word "weapon" and the verb "aim" suggest TOILET BRUSH IS WEAPON. More specifically, the form of the brush and the way it is assembled and used - presumably the liquid squirts out of the brush - suggest TOILET BRUSH IS GUN rather than, say, toilet brush is SPEAR or SWORD (see Forceville, Hekkert and Tan, forthcoming, for an attested example of TOILET BRUSH IS SWORD).

\section{What makes multimodal metaphor different from verbal metaphor?}

The conclusion is thus that metaphors can have multimodal manifestations no less than monomodal ones. We have seen, moreover, that a specific mode (here: images, sound, music, spoken or written language) drawn upon in a commercial can contribute to the identification of the metaphor as well as help cue features that are to be mapped from source to target. Multimodal metaphors share with monomodal metaphors of the verbal variety - by far the best-researched type of metaphor - that which turns them into metaphors in the first place: two phenomena belonging to different categories are represented in such a way that we are forced or invited to understand and experience one of them in terms of the other. One or more features are projected from the latter (the source) upon the former (the target), which is thereby (temporarily) transformed conceptually. However, inasmuch as language is only one of the modes that may partake into multimodal metaphor, there are dif- 
ferences as well as similarities between multimodal and purely verbal metaphors. Among the differences are the following:

The nature of the metaphorical "is" is non-verbal. The construal of verbal metaphors is aided by the rules of grammar and semantics. For one thing, the prototypical verbal metaphor has a "noun A is noun B" appearance; that is, target and source are linked by a copula. And where it is not (as happens in many cases; see Brooke-Rose 1958; Goatley 1997), grammar still often helps attest that a non-literal identification between two phenomena is proposed. In multimodal metaphors this awareness of metaphorical identification is cued by other means. The identification between two phenomena that turns them into a metaphorical target and source can be triggered in various ways. The ten cases discussed reveal the following mechanisms, separately or in combination, that contribute to the awareness that a metaphor is to be construed:

(a). Physical resemblance. This can only function as a trigger in the case of monomodal metaphors: only a visual representation can resemble another visual representation; only a sound can resemble another sound. An example of such physical resemblance is that between the toothbrush and the submarine and, arguably, that between the toilet brush and the gun. Clearly, context helps create this resemblance; there is no pre-existent similarity between target and source.

(b) Filling a schematic slot unexpectedly. The target domain - which in advertising usually is identical with, or metonymically connected to, the product - occurs in a place where one expects something else. Put differently, we encounter deviations from typical gestalts or schema's: Fully-dressed-up-Anky-on-her-dressage-horse is replaced by fully-dressed-up-Anky-on-a-bike; an unwinding silk thread reveals not the expected spindle but a plastic flacon; an air freshener on a pedestal, surrounded by sculptures, disturbs our schema for typical objects-exhibited-in-a-museum; toy cars in an otherwise completely realistic cityscape do not fit our expectations; information typically associated with wine turns out to pertain to beer. A similar subversion of a scenario occurs in the Citroen commercial: just as Ankyon-her-horse is replaced by Anky-on-a-bike, the expected enthusiastic religious testimony of the evangelists is replaced by the Citroen salesman's "testimony" of his car, by the salesman's sudden and rude interruption. That is, in the "slot" of the evangelists' testimony we get the salesman's promotion pitch.

(c) Simultaneous cueing. In the Basics and UWV cases, metaphorical identification is achieved by visually representing something or somebody in a salient manner and at the same time providing spoken (in the Basics case) or spoken and written (in the UWV case) cues pertaining to the same thing/person. In the Basics commercial the shoes are constantly centred in the frame, the camera circles around them, and there are no other candidates for being the producers of the "funny voices" dialogue we hear on the sound track. In the UWV commercial, the represented workers and the verbal qualifications - provided both orally and in written form share the obvious feature of "humanness," while the workers are given prominence by being centred in the image. Moreover, they attract attention by looking into the camera.

Perceptually rendered targets and sources are highly specific. We apprehend not just "evangelists" - we perceive these evangelists, with these faces, coats, glasses, and way of moving, with these voices. We see this particular toothbrush (with a round head that perhaps more resembles a submarine's periscope than brushes with more elongated heads do), these silly-looking toy cars. In verbal metaphors, even 
Homeric similes elaborating extensively on the nature of the mappings, readers have to imagine a lot of visual and sonic, sometimes gestural, detail. Drawing on conceptual schema's, they will retrieve from memory typical elements that belong in such schemas. In multimodal metaphors, many details need not be imagined or supplied, since they are already given. Such details are bound to evoke specific connotations, and hence will steer and constrain interpretation of metaphors in manners that are different from those cued in exclusively verbal terms. In order to gain more insight in the nature of these constraints, empirical testing is imperative.

Non-verbal communication is more easily comprehensible and has greater emotional appeal than verbal communication. Obviously, one needs to have at least some knowledge of a language to be able to construe and interpret a metaphor in that language. Metaphors whose targets and sources are cued wholly or partly via visual, sonic, or musical cues, may be understood, maybe in rudimentary fashion only, by an audience unfamiliar with the language of the country from which the metaphorical representation originates. This is not to say that non-verbal metaphors are always universally comprehensible, and if they are understood, that they are comprehended in the same way. As indicated above, cultural or national connotations adhering to a source domain are bound to affect interpretation (Kövecses 2005; (Forceville et al., in preparation a). Apart from their greater degree of comprehensibility, metaphors drawing on images, sounds, and music also, I submit, have a more intense, immediate emotional impact than verbal ones.

\section{Verbalizing multimodal metaphors}

Verbalizations of the multimodal metaphor steer interpretation. Discussing nonverbal and multimodal metaphors in academic discourse requires formulating them in the prototypical A is B format, but verbalizing non-verbal or partly-verbal information is not always a simple and self-evident action. It is a consequence of the venerable tradition of focusing on its verbal variety that metaphor scholars tend to forget that while the A-is-B format on a conceptual level underlies all metaphors, irrespective of the medium in which they occur, it is only in language that the surface manifestation and the conceptual structure can be made to resemble each other ("John is an elephant" being a verbal surface manifestation of a conceptual metaphor that, since Lakoff and Johnson 1980, would be represented as John is an elephant). For one thing, we should not forget that this apparent resemblance is due to the (very handy) convention of representing concepts in language - how else could they be subject to interpersonal reflection and scrutiny? - but that it is unlikely that this is, in fact, the way in which a metaphor is mentally represented. For another, even in purely verbal metaphors, the conceptual A-is-B level is an inferred "verbal translation" from the surface level (e.g., from "John trumpeted the news around" to JOHN IS AN ELEPHANT or JOHN IS A TRUMPETER - although in such circumstances grammar and rules governing deixis and anaphoric references tend to give strong clues that a metaphor is to be construed.

A second issue pertaining to the verbalization of metaphors on the conceptual level is that the choice for the " $\mathrm{A}$ " and the " $\mathrm{B}$ " in the metaphor may not be self-evident. Does the phrase "he attacked me fiercely in the discussion" manifest the conceptual metaphor argument is war - see Lakoff and Johnson 1980:4 et passim - or rather ARGUMENT IS STRUGGLE, or DISCUSSION IS STRUGGLE? Whereas this already can be problematic in purely verbal metaphors this is a more thorny problem in multimodal metaphors inasmuch as often target and/or source are not 
rendered verbally in the first place. That is, even more than in language, the analyst faces a choice in how to verbally represent the A IS B metaphor. Whatever formulation is chosen, it is never innocent inasmuch (1) it favours the activation of some mappings over others; (2) it suggests, possibly misleadingly, the incontrovertible presence of a metaphor as well as its stability.

Consider the Citroen commercial. Exploring the structural relationships (what Gentner and Markham, 1997 call the "aligned structure") in the domain EVANGELIST, a viewer may well derive the following analogy: the Citroen salesman is to the Citroen as the Evangelists are to the Bible, which may lead to various further elaborations of the metaphor. This means that while the formulation CITROEN SALESMAN IS EVANGELIST is a perfectly appropriate one, so is CITROEN IS BIBLE. For one thing, it is to be noted that the source, bible, unlike the source EVANGELIST, is no longer visually represented. More importantly, however, we should note that the two formulations of the "same" metaphor alert the viewer to different potential mappings. What ultimately matters, of course, is not so much how the academic analyst formulates the conceptual level of the metaphor, but how the metaphor is actually processed conceptually. In this respect Raymond Gibbs' warning to armchair theorists of metaphor is very pertinent to students of the multimodal variety as well. Gibbs points out that metaphor processing is not a monolithic event. "Many figurative-language theorists make the mistake of assuming that a theory constructed to explain one temporal moment of trope understanding can easily be generalized to account for all aspects of understanding" (1993: 256). Gibbs therefore proposes to distinguish metaphor processing into four phases: comprehension, recognition, interpretation and appreciation. The speed with which a person successfully completes each phase is bound to differ, varying from milliseconds to, potentially, years (for instance in the case of certain literary metaphors in poems, revisited throughout a lifetime). This issue requires extensive empirical research.

With regard to the "incontrovertible presence" of a metaphor suggested by the A IS B verbalization, we should reformulate the often-asked question whether "something is a metaphor" as the question whether "it is necessary/ possible/ useful to construe something as a metaphor." Indeed, Black already warned that "there is an important mistake of method in seeking an infallible mark of the presence of metaphors" (Black 1979: 36). I propose that there is a continuum from cases where metaphorical construal of two phenomena is virtually imperative because, in the given context, nothing but a metaphorical interpretation is an acceptable strategy to account for the odd juxtaposition of two phenomena, to cases where no metaphorical construal is necessary to make sense of this juxtaposition. In the latter case, the hints for metaphorical construal are so subtle that it occurs largely at the message addressee's own responsibility (see the discussion of "strong" versus "weak" implicatures as theorized by Sperber and Wilson (1995) and elaborated for a multimodal metaphor in Forceville, 1999a; see also Forceville 2005a). Consider, once more, the Citroen commercial. It is telling that the Citroen website, where the commercial is described, does not mention "evangelists" but, more generically, "sellers" going from door to door. ${ }^{4}$ Having to verbalize the metaphor, as I had to do here in order to discuss it, necessitates an explicit identification that, in the "evan-

\footnotetext{
${ }^{4}$ http://www.citroen.nl/CWH/nl-NL/Corporate/Over+Citroen/Nieuws/ 20050429Huis+aan+Huis+wint+prijs.htm.
} 
gelist" version will no doubt offend some people. While to me the visual cues for "evangelist" are inescapable, Citroen could rightfully say that this is merely my interpretation of the visual track.

\section{Multimodal metaphors in commercials: generic dimensions}

The metaphors discussed in this paper are not only characterized by their multimodal nature, they are also marked by the genre to which they belong: commercial messages. It is important to emphasize this, in order to avoid ascribing specific characteristics to their multimodal nature that are in reality due to their generic affiliation. Let me briefly elaborate on this aspect. As Ricoeur reminds us, Aristotle discussed metaphor both in his Poetics and in his Rhetoric, and while he saw no difference in structure in the two types of discourse, Aristotle emphasized that their respective functions are very different:

Aristotle defines [rhetoric] as the art of inventing or finding proofs. Now poetry does not seek to prove anything at all: its project is mimetic; its aim... is to compose an essential representation of human actions; its appropriate method is to speak the truth by means of fiction, fable, and tragic muthos. The triad of poiêismimêsis-catharsis, which cannot possibly be confused with the triad rhetoricproof-persuasion, characterizes the world of poetry in an exclusive manner (Ricoeur 1978: 13).

Clearly advertising belongs on the side of rhetoric rather than of poetry, and this codetermines our approach to it. For one thing, commercials promote a product, brand, or idea, and it is this that, as we have seen, is usually the metaphor's target. This also means that the target of the metaphor is somehow explicitly represented within the text itself; it is thus what Ricoeur calls a "metaphor in praesentia" (Ricoeur 1978: 186). Few TV advertisers would want, or dare, to dispense with visually representing their product or service. (See Forceville, 1996: 122-123 for an exception; note moreover that in the examples discussed here the products/targets are all represented pictorially - but it should be borne in mind that, theoretically at least, a product with a very specific sound could be rendered with a sonic target only.) Verbal metaphors in artistic contexts do not necessarily have an intra-textual target. That is, they can be metaphors in absentia (Ricoeur 1978: 186), as Lakoff and Turner demonstrate in their discussion of William Carlos Williams's poem "The jasmine lightness of the moon" (Lakoff and Turner 1989: Chapter 3). Similarly, multimodal metaphors may have targets that are to be supplied from extratextual information, for instance in cases of censorship (for more discussion and some examples, see Forceville, in preparation b).

There is another remarkable element in the metaphors discussed that may be due to generic considerations rather than to their multimodality: In more than half of the ten metaphors the source domain is cued before the target domain. This finding at first appears somewhat puzzling, since this is different from standard versions of verba $l$ metaphors, where the target typically appears before the source ("surgeons are butchers"/ "butchers are surgeons"). My intuition is that this "reversed order" is due to the fact that advertisers need to do whatever they can to keep viewers from zapping away during commercials. One way to achieve this is to intrigue, tease, or surprise viewers by presenting a source domain, which "comments" on the "topic" (i.e., the metaphorical target domain) before that topic - typically the product advertised - is actually identified.

A third characteristic of metaphors in advertising has been noted above: the features mapped from source to target are always positive ones - unless the target 
is not the product advertised but a rival brand to be disparaged, as in the Peugeot commercial. That is, the source domain must, in the relevant dimension, have higher status than the target - the commodity advertised. Lakoff and Turner discuss the "natural" place of things in the world in terms of the mediaeval concept of the "Great Chain of Being": there is a pyramidal hierarchy with God at the top, the angels below, high-ranking officials coming next, followed by menial workers, animals, plants, and non-animate natural things, respectively. Within these hierarchies, there are further subdivisions: for instance, the lion is the king of animals, while insects are at the very bottom of the animal hierarchy (Lakoff and Turner 1989: Chapter 4). Strictly speaking, only two examples in the ten metaphors discussed display this unequivocal difference in status, namely those in the Gazelle and Basic commercials, in both of which a commodity is personified (if we take "personification" in the broad sense of according animate attributes to non-animate things). But even though in the metaphors under discussion usually both target and source are "things," and hence evade the self-evident hierarchizing governed by the Great Chain, we nonetheless see a clear division of value between the target and the source. Wine has more prestige as a drink than beer - at least to the audience at which Brand aims its premium beer advertising. Similarly artistic sculptures rank higher in cultural value than air fresheners. A gun bestows greater power on its user than a toilet brush. Something "natural" is, in our high-tech society, held in higher esteem than something "artificial" (Dove), as is a real thing than its toy equivalent (Peugeot). The technology of a submarine is more impressive, and commands more attention than that of toothbrush; and evangelists' testimony of the Bible's "Good Message" inspires more awe and respect than a salesman's attempt at persuading a potential customer to buy. The UWV case is less self-evident. Does greater prestige accrue to a "team-player" than to a "welder"; to a "magician" than to a "lather"? The answer probably is affirmative. The UWV admonishes employers that their employees are not merely skilled workers in a manner that makes them exchangeable for other skilled workers, but have qualities that pertain to the realms that have higher prestige: a "team-player" has social skills that a welder, by virtue of his skills alone, does not have; a champion excels in what he does; a magician makes things happen no ordinary person could, a price-controller has conceptual qualities exceeding those of an overseer.

All of these aspects (metaphor in praesentia; source before target; source "higher" than target in the Great Chain hierarchy) characterize multimodal metaphor in advertising in ways not necessarily shared by other genres. Hence it is very important that these aspects are systematically investigated and tested in other genres than advertising. This, of course, requires taking into account theories of genre as well (see Altman 1999 for an excellent introduction to "genre"; for other considerations of the impact of genre-attributions on reception, see Neale 2002; Forceville 1999b, 2005a; for a study of cinematographic metaphor in feature films, see Whittock 1990).

Other variables that potentially affect the construal and interpretation of multimodal metaphors are the cultural or group-specific environment within which metaphors occur (Emanatian 1995, Gibbs and Steen 1999, Maalej 2001, 2004, Özçaliskan 2003), and the materiality of the "carrier" (paper, stone, wax, internet page ...) exemplifying the metaphor (see Kress and Van Leeuwen 1996: Chapter 7). 


\section{Acknowledgments}

I am indebted to John Kennedy and Paul Thibault for their extensive peer review comments on an earlier draft of this paper. While I undoubtedly have not been able to accommodate all their criticisms, this has certainly become a better paper thanks to them.

\section{References}

Bensdorp, Thomas, and Arjan Vergeer (2004). Geluid en de Populaire Animatiefilm: Een Cognitivistisch Onderzoek naar Betekenisvorming. ["Sound and the popular animation film: a cognitivist approach to meaning formation."] Unpublished MA thesis, Dept. of Media Studies, University of Amsterdam, The Netherlands.

Black, Max (1979). More about Metaphor. In: Andrew Ortony (ed.), Metaphor and Thought. Cambridge: Cambridge University Press, 19-43.

Bordwell, David, and Kirsten Thompson (1997). Film Art: An Introduction (fifth edition). New York etc.: McGraw-Hill.

Brook-Rose, Christine (1958). A Grammar of Metaphor. London: Secker and Warburg.

Carroll, Noël (1994). Visual Metaphor. In: Jaakko Hintikka (ed.), Aspects of Metaphor. Dordrecht: Kluwer: 189-218.

Carroll, Noël (1996). A Note on Film Metaphor. In: Noël Carroll, Theorizing the Moving Image Cam-bridge: Cambridge University Press: 212-223.

Charteris-Black, Jonathan (2004). Corpus Approaches to Critical Metaphor Analysis. London: Palgrave.

Cienki, Alan (1998). Metaphoric gestures and some of their relations to verbal metaphoric expressions. In Jean-Pierre Koenig (ed.), Discourse and Cognition: Bridging the Gap. Stanford, CA: Center for the Study of Language and Information: 189-204.

Cook, Nicholas (1998). Analysing Musical Multimedia. Oxford: Clarendon.

Cupchik, Gerald (2003). The 'Interanimation' of Worlds: Creative Metaphors in Art and Design. The Design Journal 6: 2, 14-28.

Danto, Arthur C. (1993). Metaphor and Cognition. In: Frank R. Anker-smit und J.J.A. Mooij (eds.), Metaphor and Knowledge. Dor-drecht: Kluwer: 21-35.

El Refaie, Elisabeth (2003). Understanding visual metaphors: the example of newspaper cartoons. Visual Communication 2:1, 75-95.

Emanatian, Michele (1995). Metaphor and the Expression of Emotion: The Value of Cross-Cultural Perspectives. Metaphor and Symbolic Activity 10: 163-182.

Forceville, Charles (1988). The Case for Pictorial Metaphor: René Ma-gritte and other Sur-realists. In: Aleš. Erjavec (ed.). Vestnik 9. Ljubljana, YU: Inštitut za Marksisti\#ne Študije: 150-160.

Forceville, Charles (1994). Pictorial Metaphor in Adver-tisements. Meta-phor and Sym-bolic Activity 9: 1-29.

Forceville, Charles (1996). Pictorial Metaphor in Advertising. London und New York: Routledge.

Forceville, Charles (1999a). The Metaphor Colin is a child in Ian McEwan's, Harold Pinter's, and Paul Schrader's The Comfort of Strangers. Metaphor and Symbol 14: 179-198. 
Forceville, Charles (1999b). Art or Ad? The Influence of Genre-Attribution on the Interpreta-tion of Images. Siegener Periodicum zur Internationalen Empirischen Literatur-wissenschaft [ SPIEL] 18: 279-300.

Forceville, Charles (2000). Compasses, Beauty Queens and Other PCs: Pictorial Meta-phors in Computer Adver-tisements. Hermes, Journal of Linguistics 24 [Denmark]: 31-55.

Forceville, Charles (2002a). The Identification of Target and Source in Pictorial Metaphors. Journal of Pragmatics 34: 1-14.

Forceville, Charles (2002b). Further Thoughts on Delimitating Pictorial Metaphor. Theoria et Historia Scientiarum 6 [Poland]: 213-227.

Forceville, Charles (2004). The role of non-verbal sound and music in multimodal metaphor. In: Henk Aertsen, Mike Hannay, and Rod Lyall (eds.). Words in Their Places: A Festschrift for J. Lachlan Mackenzie. Amsterdam: Faculty of Arts, VU Amsterdam, 65-78.

Forceville, Charles (2005a). Addressing an audience: time, place, and genre in Peter Van Straaten's calendar cartoons. Humor: International Journal of Humor Research 18:3, 247-278.

Forceville, Charles (2005b). When is something a pictorial metaphor? (Lecture 2 of Course on Pictorial and Multimodal Metaphor.) Available online at the Semioticon Cyber Institute. http://www.chass.utoronto.ca/epc/srb/cyber/ cforcevilleout.html

Forceville, Charles, Paul Hekkert, and Ed Tan (forthcoming). The adaptive value of metaphors. In: Uta Klein, Katja Mellmann, Steffanie Metzger (eds), Anthropology and Social History: Heuristics in the Study of Literature.

Forceville, Charles, Gerry Cupchik, and Michelle Hilscher (in preparation a). Responses to multimodal metaphor in advertising: cross-cultural perspectives [provisional title].

Forceville, Charles (in preparation b) Metaphor in pictures, sound, and moving images. [provisional title].

Freriks (2004). A pragmatic perspective on metaphor. Unpublished student paper, Department of Media Studies, University of Amsterdam, The Netherlands.

Gentner, Dedre, and Arthur B. Markham (1997). Structure mapping in analogy and similarity. American Psychologist 52: 45-56.

Gibbs, Raymond W., jr. (1993). Process and Products in Making Sense of Tropes. In Andrew Ortony (ed.), Metaphor and thought (2 $2^{\text {nd }}$ ed.), (pp. 252-276). Cambridge: Cambridge University Press.

Gibbs, Raymond W. jr. (1994). The Poetics of Mind: Figurative Thought, Language, and Understanding. Cambridge: Cambridge University Press.

Gibbs, Raymond W., jr. (1999). Intentions in the Experience of Meaning. Cambridge: Cambridge University Press.

Gibbs, Raymond W., Jr. \& Gerard J. Steen (Eds.), Metaphor in cognitive linguistics. Amsterdam: John Benjamins: 145-166.

Goatley, Andrew (1997). The Language of Metaphors. London/New York: Routledge.

Johnson, Mark (1987). The Body in the Mind: The Bodily Basis of Meaning, Imagination and Reason Chicago: University of Chicago Press, 1987.

Johnson, Mark (1993). Moral Imagination: Implications of Cognitive Science for Ethics. Chicago: University of Chicago Press. 
Johnson, Mark, and Steve Larson (2003). "Something in the Way she Moves" Metaphors of Musical Motion. Metaphor and Symbol, 18: 63-84.

Kaplan, Stuart Jay (1990). Visual Metaphors in the Represen-tation of Communication Technology. Critical Studies in Mass Communication 7: 37-47.

Kaplan, Stuart Jay (1992). A Conceptual Analysis of Form and Content in Visual Meta-phors. Communication 13: 197-209.

Kennedy, John M. (1982). Metaphor in Pictures. Perception 11: 589-605.

Kennedy, John M. (1993). Drawing and the Blind: Pictures to Touch. New Haven und London: Yale University Press.

Kennedy, John M. (forthcoming). Metaphors in Art. In Raymond W. Gibbs (ed). Cambridge Handbook of Metaphor and Thought. Cambridge: Cambridge University Press.

Kövecses, Zoltán (1986). Metaphors of Anger, Pride and Love. Amsterdam und Philadelphia: John Benjamins.

Kövecses, Zoltán (2000). Metaphor and Emotion: Language, Culture, and Body in Human Feeling. Cambridge: Cambridge University Press.

Kövecses, Zoltán (2002). Metaphor: A Practical Introduction. Oxford: Oxford University Press.

Kövecses, Zoltán (2005). Metaphor in Culture: Universality and Variation. Cambridge: Cambridge University Press, 2005.

Kress, Günther and Theo van Leeuwen (1996). Reading Images: The Grammar of Visual Design. Lon-don/ New York: Routledge.

Lakoff, George (1987), Women, Fire and Dangerous Things: What Categories Reveal about the Mind. Chicago: University of Chicago Press.

Lakoff, George (1993). The Contemporary Theory of Metaphor. In: Andrew Ortony (ed.), Metaphor and Thought (revised edition). Cambridge: Cambridge University Press, 202-251.

Lakoff, George and Mark Johnson (1980), Metaphors We Live By. Chicago/London: University of Chicago Press.

Lakoff, George, and Mark Johnson (1999). Philosophy in the Flesh: The Embodied Mind and its Challenge to Western Thought. New York: Basic Books.

Lakoff, George, and Mark Johnson (2003). Afterword, 2003. Metaphors We Live By. Chicago: University of Chicago Press, 243-276.

Lakoff, George, and Mark Turner (1989). More than cool reason: a field guide to poetic metaphor. Chicago: University of Chicago Press.

Maalej, Zouhair (2001). Processing Pictorial Metaphor in Advertising: A CrossCultural Perspective. Academic Research 1 (Tunisia, Sfax): 19-42.

Maalej Zouhair (2004). Figurative language in anger expressions in Tunisian Arabic: An extended view of embodiment. Metaphor and Symbol, 19: 51-75.

McNeill, David (1992) Hand and Mind: What Gestures Reveal about Thought. Chicago: University of Chicago Press.

Müller, Cornelia (2004). Metaphors, Dead and Alive, Sleeping and Waking: A Cognitive Approach to Metaphors in Language Use. Habilitationsschrift, Freie Universität Berlin, Germany.

Neale, Steve, ed. (2002). Genre and Contemporary Hollywood. London: British Film Institute.

Özçalisikan, Seyda (2003). Metaphorical motion in crosslinguistic perspective: a comparison of English and Turkish. Metaphor and Symbol 18, 189-229. 
Ricoeur, Paul (1978). The Rule of Metaphor: Multi-disciplinary Studies of the Creation of Meaning in Language. Translated By Robert Czerny et al. London and Henley: Routledge \& Kegan Paul.

Rohdin, Matts (2003). Summary in English in: Vildsvinet I Filmens Trädgård: Metaforbegreppet inom Filmteorin ["The Wild Boar in the Garden of Film: The Concept of Metaphor in Film Theory."] Unpublished PhD Thesis. Stockholm: Edita Norstedts Tryckeri AB, 318-29.

Rompay, Thomas van (2005). Expressions: Embodiment in the Experience of Design. Unpublished $\mathrm{PhD}$ thesis, Delft: TU.

Rompay, Thomas van, Paul Hekkert, Daniel Saakes, and Beatriz Russo (2005). Grounding abstract object characteristics in embodied interactions. Acta Pscychologica 119, 315-351.

Rozik, Eli (1994). Pictorial metaphor. Kodikas/Code 17: 203-218.

Rozik, Eli (1998). Ellipsis and the surface structures of verbal and nonverbal metaphor. Semiotica 119: 1/2, 77-103.

Sperber, Dan, and Deirdre Wilson (1995). Relevance: Communication and Cognition. Oxford: Blackwell (second edition).

Sweetser, Eve E. (1990). From Etymology to Pragmatics: Metaphorical and Cultural Aspects of Semantic Structure. Cambridge: Cambridge University Press.

Thorau, Christian (2003). Metapher und Variation: Referenzheoretische Grundlagen musikalischer Metaphorizität. Zeitschrift für Semiotik 25 (1-2): 109-124.

Turner, Mark (1991). Reading Minds: The Study of English in the Age of Cognitive Science. Princeton NJ: Princeton University Press.

Turner, Mark (1996). The Literary Mind. New York/Oxford: Oxford University Press.

Victor, Paul (2004). The Metaphorical Use of Sound in Film. Unpublished MA thesis, Dept. of Media Studies, University of Amsterdam, The Netherlands.

Whittock, Trevor (1990). Metaphor and Film. Cambridge: Cambridge University Press.

Wilson, Deirdre, and Dan Sperber (2004). Relevance Theory. In: Laurence R. Horn and Gregory Ward (eds), The Handbook of Pragmatics. Malden MA etc.: Blackwell, 607-31. 